Fecha de recepción: abril 2021

Fecha de aprobación: mayo 2021

Fecha publicación: junio 2021

\section{Migraciones en el diseño de mobiliario con perspectiva histórica. Siglos diecinueve y veinte}

Gastón Girod ${ }^{(1)}$, Alejo García de la

Cárcova ${ }^{(2)}$ e Inés Petrocchi ${ }^{(3)}$

\begin{abstract}
Resumen: Desde el comienzo de la historia del diseño industrial -con énfasis en el diseño de mobiliario- un variado universo de profesiones, materiales, tecnologías, ideologías e intereses económicos irán delineando un repertorio objetual con la consecuente instauración de un canon. Sus protagonistas, desde el siglo diecinueve hasta la actualidad, conformarán una red de movimientos migratorios motivados por intereses propios, en algunos casos, o como consecuencia del contexto político, social y cultural, en otros. El presente trabajo hace un recorrido por dichas migraciones y estudia su influencia en la formación de los profesionales, la construcción de los programas de enseñanza, la producción de la cultura material y la ampliación del canon.
\end{abstract}

Palabras clave: diseño - mobiliario - migración - historia - enseñanza - centro - periferia - canon.

[Resúmenes en inglés y portugués en la página 69]

(1) Arquitecto, especialista en diseño de mobiliario (UBA). Curso de Posgrado en Gestión de la Pyme de la Madera y el Mueble (Univ. Nac. de Gral. Sarmiento). Magister en Gestión del Diseño (UP). Profesor de la Universidad de Palermo en el Área de Diseño de Objetos y Productos de la Facultad de Diseño y Comunicación. Investigador del Ministerio de Ciencia, Tecnología e Innovación Productiva (MINCyT). Editor del libro Diseño de Mobiliario Argentino Actual y Diseño de Mobiliario 04, enfocado en la problemática latinoamericana. Escritor de la columna de diseño de la Revista D\&D.

(2) Licenciado en Diseño (UP). Diseñador Industrial (ORT). Carrera de Formación Docente (FADU/UBA). Docente de la Facultad de Arquitectura, Diseño y Urbanismo (UBA), Universidad de Palermo e Instituto de Tecnología ORT. Investigador de la Secretaría de Ciencia y Técnica (UBACyT). Se desempeña en el área de Desarrollo Académico de la Maestría en Gestión del Diseño y Publicaciones Académicas de la Facultad de Diseño y Comunicación de UP. Coordinador de comisiones en el Congreso Latinoamericano de Enseñanza del Diseño y del Coloquio de Investigación y Desarrollo en Diseño Latino. 
(3) Licenciada en Ciencias Políticas (Universidad Di Tella) y Diseñadora de Mobiliario (Universidad de Palermo). Ayudante de cátedra (UP/FADU) en Historia del Diseño Industrial 1 y 2.

\section{Introducción}

El presente ensayo evidencia la gran influencia que tuvieron las migraciones en la difusión del conocimiento en el mundo del mueble y su evolución histórica. En esta segunda entrega ordenada cronológicamente, se aborda el objeto mueble y su desarrollo en Europa y América. Se incluirán los vínculos con Oriente, que no son pocos, pero que se encuentran escasamente documentados. Se pretende analizar aspectos vinculados a la influencia de las migraciones, como una evidencia de características particulares que se dan en la configuración del mobiliario, en lo formal, técnico y funcional, dando como resultado un objeto de valor histórico, artístico, estético y simbólico. A su vez, se destacan las influencias en la consolidación de la disciplina, tanto en su profesionalización y su enseñanza, mayormente vinculada al surgimiento del Movimiento Moderno y su adaptación desde los países centrales a la periferia.

En tal sentido, la elección es arbitraria y posiblemente incompleta. Solo intenta aportar al tema desde este enfoque, ya que el mobiliario como objeto acompaña al ser humano a lo largo de su vida, reflejando momentos de su historia y evidenciando rasgos particulares de cada región, como fuente de riqueza cultural y como vínculo con la memoria.

Por último, se deja constancia que este trabajo queda sujeto a un recorte realizado por los autores, basados en las fuentes consultadas al momento de su realización.

\section{Ejes de análisis}

Centrando la atención en el diseño de mobiliario se abordan ciertos ejes que permiten ordenar el presente trabajo. Sin lugar a dudas, la enseñanza del diseño será un factor clave para comprender y rastrear el devenir de un gran número de figuras vinculadas a la disciplina que, por motivos ideológicos, políticos o profesionales, se desplazarán por el mundo, difundiendo un conocimiento novedoso y diferente al del nuevo destino que los recibirá. El segundo eje estaría delineado por los hechos políticos y sociales que impulsaron los movimientos migratorios, favoreciendo el desarrollo del diseño en algunos casos y clausurando sus posibilidades de continuidad, en otros. Esto último, sin medir las consecuencias indirectamente favorables para la propagación de la ideología del diseño moderno sumado a los avances tecnológicos y materiales como consecuencia de la Segunda Guerra Mundial y el nuevo orden internacional anclado en el dominio estadounidense de posguerra. Por último, se propone un tercer eje vinculado a las relaciones que se irán gestando entre centro y periferia, en términos de Bonsiepe (1985), donde la influencia de las vanguardias 
artísticas motivará a intelectuales latinoamericanos de variadas ramas de la cultura al vincularse con el viejo continente. Por otro lado, artistas, arquitectos y diseñadores de países centrales se sentirán atraídos en difundir sus conocimientos modernos en un terreno fértil para su propagación.

Cabe aclarar, que los tres ejes propuestos se encuentran fuertemente relacionados entre sí, impidiendo separarlos por completo. Más bien, se propone un diálogo indivisible, donde se interrelacionan e influyen unos a otros.

\section{Migraciones y diseño durante el siglo diecinueve}

En base a la bibliografía especializada en historia del diseño se pueden identificar varias figuras vinculadas al tema de migraciones que han dado origen al diseño de mobiliario moderno y a la conformación de su disciplina.

En primer lugar vale mencionar, como antecedente al siglo diecinueve, la experiencia de la comunidad religiosa Shaker. Su fundadora, la inglesa Ann Lee (1736-1784) junto con unos pocos seguidores emigraron en 1774 a Estados Unidos para escapar de la persecución que sufrían en Gran Bretaña que incluía frecuentes arrestos y prisión. Como menciona Löbach:

Después de la Guerra de la Independencia, Estados Unidos había abierto al mundo una nueva libertad. Las comunidades que por motivos estatales o religiosos no podían existir en Europa emigraron a este Nuevo Mundo. A ellas pertenecían también los shakers (1981, p. 68 y 72).

Los Shakers se instalaron en New Lebanon, en el estado de Nueva York. Desde allí la comunidad creció hasta llegar a los 6.000 miembros para mediados del siglo dieciocho. Además de sus valores religiosos, se destacan por un hacer artesanal que reflejaba su filosofía de vida desprovisto de ornamento, donde se evidencia la sencillez y la funcionalidad en el mobiliario y los objetos de uso diario. Estos aspectos se encuentran fuertemente vinculados con la conformación del diseño del siglo veinte, lo que permitiría pensar en cierto arquetipo de objetos preindustriales, principalmente los asientos, que configurarán un estándar de diseño práctico, calidad artesanal y fácil reproducción.

En segundo lugar, cabe destacar, la figura del diseñador alemán Michael Thonet (17961871), que será en la segunda mitad del siglo diecinueve uno de los precursores de la producción masiva de mobiliario en Europa. Pionero en las técnicas de curvado de la madera, hacia 1830 comenzó a investigar la posibilidad de eliminar el uso de las colas e intentar que la madera gozase de flexibilidad realizando los primeros experimentos para curvar los diversos elementos de un mueble.

En 1841 conoce al canciller austríaco Metternich, quien lo invita a Viena y logra que el gobierno financie su investigación en torno a la madera curvada. En consecuencia, logra implementar una nueva tecnología y establece su industria cerca del abastecimiento de materias primas en los bosques de haya de la región de Moravia, donde encuentra también mano de obra abundante y barata (Candilis et alt., 1981). 
Se pueden observar similitudes entre los Shakers y Thonet no solo en el empleo de la madera como principal materia prima y en la combinación de procesos artesanales e industriales en su fabricación, sino también en la oportunidad que significó la migración como recurso de expansión económica.

Asimismo, se encuentran otros diseñadores y arquitectos que realizaron viajes prolongados o migraciones por diversos motivos durante el siglo diecinueve. En muchos casos, fueron los viajes a Oriente, particularmente a Japón, los que influyeron en la constitución del diseño moderno.

Tal es el caso del arquitecto e historiador alemán Hermann Muthesius (1861-1927) que fue enviado a Londres entre 1896 y 1903 por el gobierno prusiano para estudiar los problemas de la industrialización urbana y dar cuenta de la situación del arte, la arquitectura y los avances tecnológicos británicos (Heskett, 1986, p. 65). En 1907, de regreso a su país, funda, junto a otros, la Asociación Deutscher Werkbund, un organismo multidisciplinar que sienta las bases del diseño alemán moderno al promover la racionalización de la producción. Un dato menos frecuente de encontrar en la bibliografía especializada es su estadía por cuatro años, de 1887 a 1891, en Tokio como miembro del estudio de arquitectura alemán Ende \& Böckmann (Robertson, Sharples y Nicky Imrie, 2014).

Otro nativo alemán, influyente en la conformación del art nouveau fue Samuel Bing (1838-1905) quien emigró a Francia en 1871. Luego de viajar a Japón en 1875 abrirá su primera tienda en París en 1878. Entre 1892 y 1895 realiza frecuentes viajes a Estados Unidos, donde ya había abierto una tienda en 1888. Para finales del siglo diecinueve, inaugurará en París la famosa Salon de l'Art Nouveau, donde comercializará objetos japoneses importados y expondrá a los diseñadores franceses de mobiliario más representativos. Del nombre de su tienda surge el apelativo con el cual se popularizará internacionalmente el estilo de fin de siglo (Campi, 2007; Koch, 1970, p. 1-2).

Según Koch (1970), Bing entabló relaciones comerciales y de amistad con otra figura de renombre en el diseño estadounidense, Louis C. Tiffany (1848-1933) quien también buscó inspiración en sus viajes al exterior. Como sostiene Campi: "El artista-decorador neoyorkino Louis Comfort Tiffany se interesó vivamente por el arte islámico, que conoció en su juventud visitando las colecciones de Londres y viajando al sur de España y al norte de África” (2007, p. 137). Asociado a la tienda de Bing en París también se encontraba el diseñador de muebles alemán Edward Colonna (1862-1948), que migró de Europa a Estados Unidos en 1882, instalándose en Nueva York, donde encontró empleo con Louis C. Tiffany (The Met, 2020).

Otro arquitecto que también diseñó muebles y objetos para el Salon de l'Art Nouveau fue el belga Henry Van de Velde (1863-1957) que luego de vivir en París se instala en 1898 de manera estable en Alemania, donde dirige a partir de 1902 la Escuela de Artes Aplicadas de Weimar. Considerado un hombre de vanguardia, su misión era elevar el nivel de producción de las industrias locales del arte aplicado. Su escuela, unificada con la de Bellas Artes, se convirtió en 1919 en la Bauhaus de Gropius. Como se verá más adelante, los orígenes de la Bauhaus se encuentran relacionados con la figura de Van de Velde, que era un hombre comprometido con la enseñanza de los jóvenes artistas (Hervás y Heras, 2015). Al ser socialista y pacifista, con el estallido de la Primer Guerra Mundial comienza a encontrarse en dificultades: "El director belga se ve forzado a dimitir y abandona Alemania por la fuerte 
presión. Debido a la inminente guerra se le considera un enemigo de la patria" (Hervás y Heras, 2015, p. 31). Decide refugiarse en Suiza de 1917 a 1921, para viajar a Holanda hasta 1925 y retornar a Bélgica como profesor en la Universidad de Gante y director de la Escuela de Cambre hasta 1938 (Maldonado, 2002, p. 115).

Por otro lado, se encuentra el diseñador británico Christopher Dresser (1834-1904), una figura influyente en la conformación de una estética occidental desprovista de ornamento. Como afirma Whiteway (2001) el viaje más importante de su carrera fue a Japón en 1876. Realizó una parada previa en los Estados Unidos, donde visitó la Exposición Universal de Filadelfia. "Mientras estuvo allí, vendió diseños a varios fabricantes locales y fue nombrado comprador por Tiffany \& Co. de Nueva York" (Whiteway, 2001). Sus diseños para empresas británicas posteriores a este viaje pueden identificarse como precursores del diseño moderno, evidenciándose su influencia en los objetos en cerámica y metales producidos en la escuela de Bauhaus. Más allá de no especializarse en mobiliario, los diseños de Dresser permiten comprender la influencia de Oriente en la siguiente generación y en el diseño del siglo veinte.

Por último, otro personaje que ejerció una gran influencia en los orígenes del movimiento moderno fue el austríaco Adolf Loos (1870-1933), quien viajó por Estados Unidos durante tres años, de 1893 a 1896, trabajando como albañil. En 1893 visitó en Chicago la Exposición Universal, donde tuvo su primer contacto con la Escuela de Arquitectura de Chicago (Fiell, 2012, p. 429).

Esos años serán decisivos para su formación extra-académica. El cosmopolitismo y la falta de prejuicios hacia lo extranjero que practicará a lo largo de su carrera se cimentaron en el tiempo que pasó en Estados Unidos (...) En Chicago, admira la reconstrucción de la ciudad (...) y sobre todo, la arquitectura japonesa, que contempla por primera vez y que le influirá tanto (Zabalbeascoa y Rodríguez Marcos, 1998, p. 148).

Cada una de las personalidades mencionadas en este apartado realizó su aporte a la evolución del diseño de mobiliario y de hecho forman parte -o podrían hacerlo- de la lista de Pioneros del Diseño Moderno, formulado por Pevsner (2011), texto fundacional de la historia de la disciplina. A continuación, se exponen las migraciones a partir del siglo veinte.

\section{Siglo veinte: una época plagada de migraciones}

\section{Francia como semillero del diseño moderno}

Previo al análisis de las instituciones relacionadas a la enseñanza del diseño se mencionarán algunas figuras para comprender la arquitectura y el diseño del siglo veinte, que tienen como denominador común a Francia, epicentro de la efervescencia cultural de comienzos de siglo. 
El primero de ellos es el arquitecto de origen suizo Charles-Édouard Jeanneret-Gris (18871965), inmortalizado como Le Corbusier. Luego de más de tres años de viajes por Europa occidental y oriental, en los que estuvo en contacto con Joseph Hoffmann en Viena y con Tony Garnier y los hermanos Perret en París, se traslada a Alemania, para trabajar con Peter Behrens, el maestro de Gropius y Mies van der Rohe. "Behrens, un artista, será el complemento ideal a Perret, un constructor, en su formación" (Zabalbeascoa y Rodríguez Marcos, 1998, p. 198). Finalmente, en 1917 se instala en París donde formará su estudio de arquitectura y mobiliario. Cabe destacar su presencia e influencia den el Estilo Internacional tanto en oriente como en el centro y la periferia. Tal como señalan Zabalbeascoa y Rodríguez Marcos (1998): "Le Corbusier construirá entre tanto en Argentina, Japón, Alemania y Estados Unidos” (p. 206).

Vale la pena mencionar dos figuras femeninas cercanas a Le Corbusier que también dejaron su huella en el diseño de mobiliario del Movimiento Moderno, aportando sus conocimientos provenientes de la cultura japonesa, tema recurrentemente referido en el presente trabajo.

Charlotte Perriand (1903-1999) fue una arquitecta y diseñadora francesa que trabajó en el estudio de Le Corbusier como responsable de mobiliario e interiores desde 1927. En 1940 recibió una misiva del Ministerio de Comercio e Industria de Japón, solicitándole ser Consejera Técnica en Artes Industriales, invitación avalada por Junzo Sakakura como testimonio de la amistad nacida cuando ambos colaboraban en el estudio de Le Corbusier. Debido a ello y a la guerra que afligía a Europa, decide trasladarse a Japón. En 1941 organizó en la ciudad de Tokio una exposición, que fue de gran influencia -titulada Selección, Tradición, Creación - donde recreó las distintas estancias de una casa moderna japonesa y mostró una compilación de productos tradicionales y nuevos, realizados bajo su dirección. (Heroínas del espacio, 2007, p. 215). "Durante su estancia en aquel país profundizó en los materiales y las técnicas artesanales de construcción de muebles, lo que le permitiría realizar interesantes piezas en las que muestra la fusión de las influencias occidentales y orientales" (Torrent y Marín, 2005, p. 244). Como sostiene Espegel (2007):

Perriand fue capaz de dar respuesta a la gran pregunta que se cuestionaban los japoneses en ese momento, la integración del mundo moderno preservando una cierta tradición (...) es Charlotte Perriand, mediante su espíritu crítico y su sentido ético de la modernidad, quien introduce un respetuoso Occidente en Oriente (2007, p. 216).

Bloqueada por la guerra, Perriand consiguió abandonar Japón en 1943, huyendo a Vietnam, desde donde fue repatriada a Francia recién en 1946. Aprovechó su estadía allí para realizar trabajos con bambú.

Por su parte, la arquitecta anglo-irlandesa Eileen Gray (1878-1976) es conocida principalmente por su diseño de mobiliario moderno y por incorporar el trabajo de la laca al estilo internacional. "Tras un primer viaje a París en 1900 donde descubre la intensidad cultural de la ciudad, Gray decide establecerse en ella dos años más tarde, abandonando así el Londres restrictivo y victoriano" (Espegel, 2007, p. 101). Asiste a escuelas de arte de renombre y en 1907 comienza su aprendizaje con el maestro de la laca japonés afincado en 
París, Seizo Sougarawa. Animada por Le Corbusier se forma como arquitecta autodidacta, en los albores del surgimiento del Movimiento Moderno. Incluso para Espegel, logra ser precursora en el uso de nuevos materiales:

(...) muchos de los diseños de mobiliario de acero cromado de Gray precedían tanto a los de Charlotte Perriand y Le Corbusier (quienes mostraron sus primeros muebles cromados en 1928), como a los de Mies van der Rohe o Marcel Breuer (2007, p. 127).

Por último, se destaca la figura del ingeniero francés Raymond Loewy (1893-1986), protagonista indiscutido del diseño industrial, tal como se lo concibe en la actualidad. En 1919, luego de la Primera Guerra Mundial emigra hacia los Estados Unidos y se instala en Nueva York trabajando primero como ilustrador y diseñador de escaparates hasta rediseñar una máquina copista que lo posicionará como el precursor del concepto de carcaseo y styling. De tal manera, iniciará una carrera que lo ubicará como el principal diseñador industrial de su generación como así también el de un modelo de profesional versátil que sabe responder a las necesidades de cada cliente, sin importar el rubro, con el diseño de electrodomésticos, objetos y mobiliario (Schönberger, 1990; Loewy, 2000; Gay y Samar, 2004).

\section{La enseñanza del diseño y sus repercusiones globales}

A continuación se analizarán las interconexiones entre algunas de las más importantes escuelas de diseño del siglo veinte como lo son la Bauhaus (1919-1933), Vchutemas (19201930), Cranbrook (1932) y Ulm (1953-1968). Se hará un mayor énfasis en la Bauhaus dada la intensa actividad y movimientos migratorios de sus directores, profesores, invitados y alumnos. Esto se debe también a que se dispone de mayor información que del resto de las escuelas, sobre todo de Vchutemas.

La escuela rusa Vchutemas surge bajo decreto de Lenin en 1920. Entre sus profesores de renombre se encuentra el artista y diseñador constructivista Kasimir Malevich (18791935), quien registra un viaje a la escuela de Bauhaus en 1927, intentando mejorar su situación laboral luego del ascenso de Stalin al poder. Stachelhaus (1991) comenta que "este fue su primer viaje al extranjero y también fue el único" (p. 169). En Berlín dictó conferencias y visitó la escuela en su sede de Dessau, sin éxito. Si bien se publicó el libro de la Bauhaus No11 dedicado a su obra, las autoridades adujeron la falta de presupuesto para poder contratarlo, por lo que unos meses después regresará a su país.

Cercano a Malevich, el también artista constructivista El Lissitzky (1890-1941) se traslada a Berlín en 1921 al asumir el cargo como embajador cultural de Rusia en Alemania. Allí establecerá contactos entre los artistas rusos y los alemanes. Convencido de que el constructivismo debía ser un movimiento internacional, logra influenciar a figuras destacadas tanto de la Bauhaus como del movimiento neoplasticista (Wilhide, 2017, p. 122). Aprovechará para estudiar en la Escuela Técnica en Darmstadt y viajará por Italia y Francia entre 1909 y 1914 (Barron y Tuchman, 1980). 
Por su parte, la Bauhaus fundada por Walter Gropius (1883-1969) en 1919, en el contexto de la incipiente y breve República de Weimar, surge como consecuencia de una Alemania derrotada durante la Primera Guerra Mundial y ve su final en 1933 con la llegada del nazismo al poder. Semillero del diseño industrial moderno, fue una institución donde se aplicaron nuevas y revolucionarias concepciones pedagógicas en el campo de la educación estética (Gay, 2004, p. 89).

Para entender la importancia de esta escuela de arte, arquitectura y diseño es necesario detenerse en el crisol de personalidades que la formaban. Esa diversidad también fue consecuencia de las migraciones que se dieron para la constitución de su ecléctico grupo de profesores, provenientes del continente europeo. Luego, se sumarán alumnos que vendrán de lugares tan remotos como Japón, como el caso de Takehiko Mizutani (1898-1969) que se incorporará entre 1927 y 1928 (Fiedler y Feierabend, 2000, p. 377).

Es importante destacar que la escuela en sí misma representa quizás la migración de mayor envergadura referida al diseño. Esto se debe a que gran parte de su plantel docente y estudiantil sufrirá los vaivenes políticos y sociales, que redundarán en la mudanza de su sede en dos ocasiones, de la ciudad de Weimar a Dessau, y de allí a Berlín. Posteriormente, se producirá lo que se conoce como la diáspora Bauhaus, por tratarse de una mayoría de personas pertenecientes a la colectividad judía o de tendencias izquierdistas, en clara oposición al régimen en ascenso.

Entre los profesores que llegarán para participar de este proyecto, se destaca la figura del húngaro Lázsló Moholy-Nagy (1895-1946), quien luego de haber estado tres años entre Viena y Berlín, recala finalmente en 1923 en Dessau, donde se hace cargo del curso preparatorio y del taller de metal como maestro de la forma. Con Wassily Kandinsky (18661944), que se había incorporado en 1922, son la presencia del constructivismo ruso en la Bauhaus (Torrent y Marín, 2005, p. 100).

En 1923, también procedente de Hungría, llega Marcel Breuer (1902-1981), quien se incorpora como alumno hasta 1924, cuando obtiene el título de oficial. Luego de una estancia en París, retorna a la escuela como director del taller de muebles entre 1925 y 1928. En su taller, se desarrollaron los primeros proyectos de muebles de tubos de acero para el interior de casas particulares. Breuer comienza a diseñar con caños de acero curvados, recuperando el concepto ideado por Thonet en madera de haya e inspirado también por el diseño de las bicicletas modernas. En concreto, las sillas de Breuer permanecen en la historia del diseño por desarrollar unos planteamientos muy novedosos que se afianzarán en el futuro. Igualmente innovadores son los primeros proyectos de sillas en voladizo de Mies Van der Rohe y de Mart Stam, que serán mencionados más adelante.

Luego de su experiencia en la escuela, Breuer se relocaliza primero en Berlín donde comienza su labor como arquitecto, a la par que continúa con el diseño de mobiliario en caño curvado, cuero y esterilla. Estos serán incorporados a la producción y como parte del catálogo de ventas de la empresa Thonet, dándole visibilidad y presencia internacional. Otro estudiante devenido en profesor es Josef Albers (1888-1976), quien ingresa en 1920 y entre 1928 y 1933 se encarga del curso preliminar. Durante su estadía, realizará una importante labor artística y de diseño de muebles y objetos (Droste, 1991, p. 242). Su mujer Anni Albers (1899-1994), también se convierte en profesora, luego de haber sido alumna, dirigiendo a partir de 1931 el taller de tejidos. 
Otro miembro de la Bauhaus importante por su proyección posterior es el suizo Max Bill (1908-1994) quien ingresa como alumno en 1927 y permanece hasta 1929. "Su inclinación por la arquitectura lo lleva a París en donde será ayudante de Le Corbusier y de Hoffmann" (Bozzano, 1998, p. 32). Bill será reconocido como el artista concreto más influyente y como el arquitecto responsable de la sede de la Escuela Superior de Diseño en la ciudad de Ulm, donde será su director desde su fundación en 1955 hasta su alejamiento en 1957. Otra figura que se destaca por las influencias y legado de proyección internacional a partir de su participación en la Bauhaus es el arquitecto Hannes Mayer (1889-1954). De nacionalidad suiza, llega primero a Berlín en 1909 y entre 1927 y 1930 se desempeñará como profesor y segundo director de la escuela, en la sede de Dessau. Su ideología comunista lo llevará a comprometerse con la construcción de viviendas sociales y mobiliario funcional, de fácil producción y accesible y, al mismo tiempo, lo desplazará de la dirección de la Bauhaus. En 1930, migrará junto a siete ex-alumnos de la Bauhaus a la Rusia comunista donde permanecerá hasta 1936. Retornará a su país natal -expulsado por el gobierno de Stalin- hasta el inicio de la Segunda Guerra Mundial que lo llevará a radicarse durante diez años en México invitado por el Congreso de Trabajadores de América Latina, la Unión de Arquitectos Socialistas (UAS) y el Instituto Politécnico Nacional. El caso de Meyer se destaca por tratarse de una figura que migró en varias ocasiones, fuertemente impulsado por cuestiones políticas e ideológicas, como sucedió también en otros casos. Como señala Ynzenga Acha:

Koop comenta algunas de las posibles razones que motivaron la ida a Rusia de tan gran cantidad de arquitectos y técnicos: en primer lugar, ideas compartidas sobre el papel de la arquitectura como instrumento de transformación social; y además, los efectos de la depresión económica de 1929; la subida de Hitler al poder, la ascendencia judía de algunos de ellos y el anti judaísmo, la creencia en que en la URSS podrían desarrollar los principios del movimiento moderno (Ynzenga Acha, 2017, p. 90).

El tercer director de la escuela y el más consagrado arquitecto es Ludwig Mies van der Rohe (1886-1969), quien participará del proyecto Bauhaus suplantando a Meyer en Dessau, viéndose obligado a cerrar dicha sede por presiones políticas del régimen en ascenso y trasladando por un breve lapso a alumnos y docentes a una sede en Berlín.

Con respecto a las personalidades visitantes, externas a Bauhaus, se destaca la influencia que tuvo el holandés Theo van Doesburg (1883-1931), uno de los creadores del movimiento neoplasticista De Stijl, que llega a Weimar en 1921 con la intención de conseguir un puesto como profesor en la escuela. Sus ideas no convencerán a Gropius por lo que dictará cursos por fuera de la institución, impartiendo sus teorías y creando disenso entre estudiantes y docentes. Como señala Gay:

(...) desde que llegó comenzó a dictar cursos por su cuenta, a los que asistieron muchos alumnos de la Bauhaus, entre los que podemos mencionar a Marcel Breuer, que más tarde, como docente, estuvo encargado del taller de muebles, y en cuyas primeras realizaciones se nota la influencia de Gerrit Rietveld (Gay, 2004, p. 99). 
Otro personaje relevante para la historia del mobiliario es el arquitecto holandés Mart Stam (1899-1986) que si bien declinó la oferta de Gropius de ser director de la Bauhaus impartió un curso allí como invitado entre 1928 y 1929, en el cual los estudiantes elaboraron proyectos para el concurso de la colonia Haselhorst en Berlín (Hervás y Heras, 2015, p. 130). Previamente trabó amistad en Berlín con El Lissitsky, lo que lo llevó a convertirse al constructivismo y al comunismo. En 1930 forma parte de la comitiva de Meyer y su grupo de colaboradores de la Bauhaus que se instala en Rusia.

Cabe hacer una mención especial a la denominada diáspora Bauhaus.

El ascenso al poder del nacionalsocialismo en Alemania y su posterior expansión por Europa, empujó a muchos diseñadores al exilio al final de los años 30. Muchos de ellos hallaron acogida en Estados Unidos, donde continuaron su actividad profesional y pedagógica (Torrent y Marín, 2005, p. 282).

Esto significó una proyección para los postulados de esta escuela-como para las carreras individuales de sus protagonistas- por los lamentables hechos socio-políticos que produjeron la diáspora al resto del mundo. La actividad de estos maestros fue determinante a la hora de difundir las ideas del funcionalismo racionalista del Movimiento Moderno.

En el caso de Gropius, luego de renunciar a la dirección de la Bauhaus en 1928, realizará un primer viaje a Estados Unidos para estudiar el diseño de la vivienda y los nuevos métodos de construcción (Zabalbeascoa y Rodríguez Marcos, 1998). Con el ascenso de Hitler al poder, los ataques de prensa y la presencia de la Gestapo en su estudio, decidirá instalarse unos años en Londres, entre 1934 y 1937, donde será contratado como consultor de diseño para una compañía de aluminio y luego para una empresa de muebles.

(...) Además, será invitado a formar parte de la MARS, una asociación dedicada a promover la arquitectura moderna que contará entre sus miembros a Moholy-Nagy y Marcel Breuer, apoyados por Gropius a establecerse en Londres. El contacto con antiguos profesores y alumnos de la Bauhaus se convertirá en una constante a lo largo de toda su vida (Zabalbeascoa y Rodríguez Marcos, 1998, p. 168).

En 1937 se traslada definitivamente a Estados Unidos y es nominado profesor en la Escuela de Diseño de la Universidad de Harvard con el encargo de acometer una profunda reforma en los métodos de enseñanza. En 1938 "vuelve a cubrir el cargo de presidente del Departamento de Arquitectura y de fellow del American Institute of Architecture" (Maldonado, 2002, p. 183). Simultáneamente, abre un estudio en sociedad con Marcel Breuer, que mantendrá hasta 1942. Ya retirado, viaja por Sudamérica y Japón, la última gran relevación de su vida. "Allá a donde vaya tendrá siempre como anfitrión a un antiguo alumno de la Bauhaus, ya sea en Hong Kong, Calcuta o Atenas" (Zabalbeascoa y Rodríguez Marcos, 1998, p. 169).

Por su parte, Breuer tuvo que exiliarse en 1933 debido a su religión entre Suiza y Budapest, donde dividirá su actividad. Para 1935, se muda a Londres donde abre un estudio junto a F.R.S. Yorke. Se destaca de este periodo los diseños en madera multilaminada y curvada, 
para la empresa Isokon. Invitado por Gropius, se instalará definitivamente en Estados Unidos en 1937 donde impartirá clases en la Escuela de Diseño de Harvard hasta 1941 dedicándose luego y con éxito a proyectos arquitectónicos privados y corporativos (Droste y Ludewig, 1992).

Moholy-Nagy, a su vez, emprende su escape de Alemania en 1934 dirigiéndose a Amsterdam y al año siguiente, a Londres. Terminará estableciéndose finalmente en Estados Unidos en 1937, donde fundará primero y sin éxito la Escuela de Diseño New Bauhaus en Chicago y luego la actual School of Design (Droste, 1991, p. 249).

En el caso de Albers, emigrará junto a Anni a Estados Unidos en 1933. Ambos se incorporarán como profesores al Black Mountain College en Carolina del Norte hasta 1949. Albers introdujo en dicha institución su famoso programa del curso preliminar de la Bauhaus, en el cual estimulaba a los estudiantes con ejercicios libres para que ensayaran la técnica y la creatividad necesarias para diseñar. Desde 1936, la pareja realizará catorce viajes por América Latina en los que visitarán México, Cuba, Perú y Chile y dejarán plasmada la influencia de la cultura prehispánica en sus obras. Entre 1950 y 1959, Albers será director del Departamento de Diseño de la Universidad de Yale en Connecticut. En 1953, regresará a su país natal como profesor invitado de la Escuela de Diseño de Ulm para finalmente retirarse en 1958 en Connecticut (Droste, 1991, p. 242).

Por último, Mies van der Rohe, será forzado por el régimen en ascenso a cerrar la sede provisoria de la Bauhaus que había montado en Berlín. "Cuando comprendió que las preferencias de Hitler se inclinaban hacia un monumentalismo neoclásico cuyo máximo exponente sería Albert Speer, decidió abandonar Alemania. Es posible que fuese una decisión más estética que ética pero en 1937 llegaba a Nueva York" (Zabalbeascoa y Rodríguez Marcos, 1998, p. 191). El Armour Institute of Technology de Chicago le había hecho una oferta para dirigir la Escuela de Arquitectura, cargo que ocupó entre 1938 y 1958. Según Droste, "Al mismo tiempo trabaja en su estudio en Chicago. Innumerables construcciones que determinan la arquitectura del siglo veinte, sobre todo en Chicago y Nueva York" (1991, p. 249). Otra migración significativa a Estados Unidos fue la del arquitecto finlandés Eliel Saarinen (1873-1950) emigra con su esposa Loja en 1922 tras ganar el segundo premio del concurso de Chicago Tribune Tower. Fue profesor invitado de arquitectura en la Universidad de Michigan. En 1923 conoce al magnate de la prensa y filántropo George C. Booth, quien le encarga el proyecto de la Cranbrook Educational Community. En 1932 se inauguró oficialmente la Cranbrook Academy of Arts de Detroit, de la que fue el primer presidente. Bajo su dirección, la academia llegó a ser la primera institución de diseño de Estados Unidos y formó a muchos de los principales talentos del diseño del país (Fiell, 2012, p. 623). Como sostienen Torrent y Marín (2005), al proceder Saarinen de la tradición humanista del diseño escandinavo, contribuyó a elaborar un concepto de producto diferente al estilismo estadounidense que presentaba ciertos indicios de agotamiento.

Respecto a lo acontecido en la Europa de posguerra, la concepción de diseño instaurada por la Bauhaus será retomada luego del nazismo y de la Segunda Guerra Mundial por la Escuela Superior de Diseño de Ulm fundada en 1955. Como se mencionó, su primer rector fue Max Bill, ex alumno de la Bauhaus. Lo sucede en 1957 el diseñador argentino Tomás Maldonado (1922-2018), determinando una formación más científica y metodológica, vinculada al diseño y a otras áreas que se fueron consolidando a partir de la segunda 
mitad del siglo veinte. Esto significó un puntapié para la subsiguiente creación de muchas otras escuelas modernas que incorporarán paulatinamente las disciplinas del diseño en todo el mundo. Según Bürdek, antiguo alumno de Ulm:

La influencia de la Escuela de Ulm se hace patente sobre todo fuera de Alemania ya que, tal como sucediera con el éxodo de los miembros de la Bauhaus después de 1933 -aunque por diferentes motivos-, muchos miembros de Ulm buscaron nuevas posibilidades de trabajo en países bien diversos de todo el mundo (2007, p. 47).

Asimismo, Torrent y Marín señalan: "Por sus aulas pasaron 200 profesores invitados y 640 estudiantes de 49 nacionalidades diferentes que, en muchos casos, se encargarían de difundir sus enseñanzas" (2005, p. 302). De hecho, algunos de sus miembros facilitaron la creación de la Escola Superior de Desenho en Río de Janeiro y el Laboratorio Associado en Florianópolis en Brasil, el National Institute of Design y el Industrial Design Center en India, la Oficina Nacional de Diseño Industrial en Cuba y un curso de posgraduados en la Universidad Autónoma Metropolitana de México (Bürdek, 2007, p. 47 y 48).

Otro estudiante de Ulm devenido en profesor migrante es el diseñador alemán Gui Bonsiepe (1934). En 1968, luego del cierre de la institución, emigra a Chile para trabajar en la Organización Internacional del Trabajo. Luego del golpe al presidente Allende en 1973 se traslada a Argentina donde trabaja en el Centro de Investigaciones de Diseño Industrial (CIDI) y desarrolla proyectos arquitectónicos y de mobiliario para los estadios del Mundial de 1978. En 1981 se muda a Brasil donde trabaja como docente en la Escuela Superior de Diseño Industrial en Río de Janeiro, para asentarse finalmente en Estados Unidos en 1987.

\section{Migraciones y diseño en América Latina: centro y periferia}

Cabe destacar algunas figuras que registran migraciones significativas para relacionar los países periféricos, como los de América Latina, con los centrales de Europa.

En primer lugar, se encuentra el caso de la arquitecta cubana Clara Porset (1895-1981), quien tuvo una educación poco común para las mujeres de su generación con un Bachillerato en Artes de la Universidad de Columbia en Nueva York, estudios de arquitectura y diseño de mobiliario con Henri Rapin y cursos en La Sorbona, la Escuela de Bellas Artes y el Museo del Louvre en París. En 1932 regresó a Cuba para dedicarse de lleno al diseño de muebles en residencias, clubes, hospitales y escuelas, introduciendo las ideas del movimiento moderno en la isla. Por cuestiones políticas debe emigrar de su país. "En 1935, ante la imposición de otro gobierno espurio, se unió a la huelga general y militó activamente en la resistencia popular" (Salinas Flores, 2006, p. 20). Se instaló en México, donde conocerá a su marido, el pintor y muralista Xavier Guerrero y terminará desarrollando su carrera profesional. Dos años más tarde viajó a Estados Unidos, donde hizo un curso en el Black Mountain College, a cargo de los Albers, con quienes forjó una fuerte amistad. Sus años de formación concluyeron, según su propio testimonio, al lado de Hannes Meyer, que fue su amigo y mentor durante los diez años que vivió en México (Salinas Flores, 2006, p. 19). 
Por otro lado, se encuentra la arquitecta y diseñadora Achillina Bo (1914-1992), conocida como Lina Bo Bardi. Italiana de nacimiento, en 1946 emprende un viaje a Brasil para acompañar a su marido, el periodista Pietro María Bardi, que había recibido una invitación para promocionar el arte italiano. En 1947 se mudan definitivamente con motivo de su designación como creador y director del Museo de Arte de San Pablo. (Diaz, 2019, p. 92). En 1948, Bo Bardi funda, junto con Giancarlo Palanti (1906-1977), -otro arquitecto italiano radicado en Brasil-, el estudio Palma y diseñan muebles de madera prensada y maderas nativas, inspirados en los diseños vernáculos de sus viajes por el noreste brasilero. Con respecto a los movimientos migratorios en Argentina, tanto Blanco (2016) como Levisman (2017) dan cuenta de las personalidades del diseño internacional que se radicaron, estuvieron de visita o realizaron trabajos específicos y que ayudaron a forjar el diseño de mobiliario argentino.

En 1940, llega a Buenos Aires Jean Michel Frank (1895-1941), decorador francés exponente del estilo Art Déco. Escapando de la guerra e invitado por Ignacio Pirovano, decorador argentino fundador de la empresa de mobiliario Comte que había conocido en París, se une como director artístico de la misma. Se encarga del mobiliario y decoración del Hotel Llao Llao en Bariloche junto al arquitecto Alejandro Bustillo, el lobby y varios departamentos del Edificio Kavanagh, entre otros trabajos. Según expresa Blanco: "Podemos decir que fueron antecedentes al diseño argentino ya que varios de los arquitectos, que luego fueron protagonistas del mismo, conocieron la obra de Jean Michel Frank, y estuvieron relacionados con Comte y los Pirovano" (2016, p. 19 y 20) Asimismo, Frank proyectó modelos que surgieron de sus observaciones sobre las habilidades argentinas en la elaboración del cuero, inspirada en los usos del hombre de a caballo (Levisman, 2017, p. 34).

Otro caso de migración es el del catalán Antonio Bonet Castellana (1913-1989) que residió en Buenos Aires gran parte de su vida. Finalizados sus estudios de arquitectura, viaja a París donde se incorporó al estudio de Le Corbusier. Luego del estallido de la guerra civil española, emigra a Argentina y funda en 1938, junto a los argentinos Jorge Ferrari Hardoy y Juan Kurchan, el grupo Austral que es responsable del diseño del sillón BKF, entre otros trabajos. Bonet también realizó obras arquitectónicas en Buenos Aires, Mar del Plata, Uruguay y en Paraguay.

Asimismo, entre las décadas del 40 y 50 arriban un conjunto de diseñadores vieneses, entre los cuales se destacan Martín Eisler (1913-1977) y los hermanos Walter (1905-1974) y Hermann Loos (1921- 2004) (Blanco, 2016, p. 21). Todos ellos se establecieron en Buenos Aires y trabajaron como arquitectos y diseñadores de mobiliario. En 1945 Eisler funda Interieur Forma, junto con otros compatriotas Suzy Aczel y Arnold Hakel, e introduce muebles con sus propios diseños, en los cuales utiliza maderas exóticas locales como jacarandá y civiona (modernabuenosaires.org).

Vale recordar también la visita del mencionado Breuer para dictar una serie de conferencias en la UBA (Levisman, 2017, p. 55). Su paso quedará plasmado en la única obra de su autoría en la región: el parador Ariston, localizado en las afueras de la Ciudad de Mar del Plata, inspirada la forma de su planta en el sillón BKF.

Paralelamente, se efectúan migraciones en sentido inverso, con la emigración de algunos profesionales argentinos al exterior. Cabe mencionar algunas figuras que, si bien no se destacaron especialmente en mobiliario, representan migraciones significativas para la co- 
nexión de los países periféricos con los centrales. Quizás, el más importante sea el caso ya comentado de Maldonado en la escuela de Ulm que continúa con su estadía europea al radicarse definitivamente en Milán, donde sobresale en la práctica profesional del diseño y la docencia con la creación de la carrera de Diseño de Productos en el Politécnico di Milano. A partir de los años 70, emigra Roberto Napoli a Milán, Héctor Compaired se instala en Barcelona, donde ya residían Jacobo Glanser, Jorge Pensi, Alberto Lievore y Norberto Chavez y Frank Memeldorsff se ubica en Madrid (Blanco, 2016, p. 24).

A modo de cierre, y en un claro interés por ampliar el canon, se mencionarán someramente las migraciones de algunas figuras poco visibilizadas en el diseño de mobiliario de América Latina. Estos datos fueron recogidos del reciente trabajo de Diaz (2019). El argentino Gonzalo Córdoba se radicó en Cuba y el brasilero Joaquín Tenreiro -que diseñó para Oscar Niemeyer- vivió en Portugal. El venezolano Miguel Arroyo, el puertorriqueño Duncan del Toro y los colombianos Jaime Gutiérrez Lega (con estudios en Finlandia) y Oscar Muñoz (con estudios en Italia e Inglaterra) desarrollaron su actividad profesional y/o estudios en Estados Unidos. Por último, se registran las inmigraciones del alemán Michael Weiss Egner que, luego de pasar unos años en Holanda, será invitado por Bonsiepe a Chile para realizar mobiliario social y del holandés Cornelis Zitman, que se radicará en Venezuela durante la posguerra ejecutando una amplia labor en el diseño de muebles.

\section{Conclusiones}

Además del progreso que significó para la sociedad moderna del siglo diecinueve y veinte el avance de la industrialización - de la mano de nuevos materiales y tecnologías que permitieron una nueva escala y diversas estéticas vinculadas a éstas-, y los movimientos migratorios sucedidos a lo largo de todo el periodo analizado, no se debe dejar de lado otro punto decisivo en la configuración del entorno humano de dicha época. Nos referimos a las variadas enfermedades que acecharon a la población, principalmente en las crecientes ciudades modernas. Quizás la tuberculosis sea la más drástica y que puso de manifiesto que el diseño de mobiliario -más que nunca en relación con su entorno construido- debía dar soluciones urgentes a una corriente higienista abrazada por los arquitectos y diseñadores modernos. De aquí se desprende la idea del empleo de materiales sencillos de limpiar, livianos para ser movidos y con una estética vinculada a la higiene y la pulcritud, desprovista de todo ornamento.

La mayoría de los diseñadores presentados a lo largo del presente trabajo, formaron parte de este nuevo Movimiento Moderno, que se propuso dar respuestas a enfermedades tales como la tuberculosis, la malaria, la gripe y el cólera. Esto se manifestó en sus diseños concebidos bajo la idea de obra de arte total, donde cada objeto forma parte de un todo, centrado en la arquitectura. El caso que mejor da cuenta de lo antedicho podría ser el Sanatorio Paimio de Alvar Aalto. Pero también se puede vincular toda la experiencia moderna que significó el Bauhaus y su influencia internacional.

El contexto actual de pandemia, provocará infinidad de migraciones de diferentes tipos. Sin duda muchas estructuras están mutando, nuevas geografías para vivir, nuevas formas 
de habitar, nuevas formas de pensar, de diseñar, nuevas formas de producir, nuevas formas de relacionarse, nuevas formas de trabajar, nuevas formas de pensar y nuevas formas de ser. En este sentido, se podría decir que, desde los albores de la arquitectura y el diseño modernos hasta nuestros días, ambas disciplinas tomaron partido por un compromiso social ineludible. Así se manifiesta también en la actualidad, con el surgimiento de una nueva pandemia, donde el diseño, el interiorismo y la arquitectura se proponen dar respuestas urgentes a problemáticas actuales.

Se concluye el presente ensayo con las palabras de Colomina, haciéndolas extensivas al diseño:

La historia de la arquitectura es la historia de las enfermedades infecciosas. No se pueden separar. (...) Las ciudades siempre han respondido a la enfermedad. Están hechas a base de capas y capas de respuestas a epidemias y a amenazas de enfermedad de todo tipo (El Confidencial, 2020).

El diseño debe estar presente siempre en estas discusiones, al margen de intereses corporativos y en pos de una sociedad más sana y con igualdad de condiciones.

\section{Bibliografía}

Barron, S. y Tuchman, M. (1980). The Avant-Garde in Russia, 1910-1930: New Perspectives. U.S.A.: Library of Congress.

Blanco, R. (2007). Notas sobre Diseño Industrial. Buenos Aires: Nobuko.

Blanco, R. (2016). Diseño Argentino Permanencias. Buenos Aires: Diseño Editorial.

Bonsiepe, G. (1985). El diseño de la periferia. Debates y experiencias. México: Gustavo Gili.

Bozzano, J. N. (1998). Proyecto: razón y esperanza. Escuela superior de diseño de Ulm. Capital Federal: Editorial Universitaria de Buenos Aires.

Bürdek, B. E. (2007). Diseño. Historia, teoría y práctica del diseño industrial. Barcelona: Gustavo Gili.

Campi, I. (2007). La idea y la materia. Vol. 1: El diseño de producto en sus orígenes. Barcelona: Editorial Gustavo Gili.

Candilis, G. et alt., (1981). Muebles Thonet. Historia de los muebles de madera curvada. Barcelona: Editorial Gustavo Gili.

Diaz, P. (2019). ABC del Diseño Industrial Latinoamericano. España: Caligrama.

Droste, M. (1991). Bauhaus. 1919-1933. Colonia: Taschen.

Droste, M. y Ludewig, M. (1992). Marcel Breuer.Colonia: Taschen.

El confidencial (2020). ¿Casas y escuelas anticovid? El ejemplo de cómo la arquitectura moderna frenó la tuberculosis. Recuperado de https://www.youtube.com/watch?v=qsa ZPRbh3cs

Espegel, C. (2007). Heroínas del espacio. Mujeres arquitectos en el Movimiento Moderno. Buenos Aires: Nobuko.

Fiedler, J. y Feierabend, P. (2000). Bauhaus. Printed in Spain: Könemann. 
Fiell, C. y Fiell, P. (2012). Diseño del siglo XX. Colonia: Taschen.

Gay, A. (2004). La Bauhhaus. En Gay A. y Samar, L. (2004). El diseño industrial en la historia. Córdoba: Centro de Cultura Tecnológica.

Gay A. y Samar, L. (2004). El diseño industrial en la historia. Córdoba: Centro de Cultura Tecnológica.

Hervás y Heras, J. (2015). Las mujeres de la Bauhaus: de lo bidimensional al espacio total. Ciudad Autónoma de Buenos Aires: Diseño Editorial.

Heskett, J. (1986). German Design. 1870-1918. Great Britain: Taplinger Publishing Co.

Koch, R. (1970). Itroduction. En S. Bing: Artistic America, Tiffany Glass and Art Nouveau. U.S.A.: The Massachusetts Institue of Technology.

Levisman, M. (2017). Diseño y producción de mobiliario argentino 1930-1970. Buenos Aires: Arca.

Levisman, M. (2015). Diseño y producción de mobiliario argentino 1930-1970. Buenos Aires: Arca.

Löbach, B. (1981). Diseño industrial. Bases para la configuración de los productos industriales. Barcelona: Editorial Gustavo Gili.

Loewy, R. (2000). Industrial design. Spain: Laurence King Publishing.

Lucie-Smith, E. (2005). Furniture. A concise history. Singapore: Thames \& Hudson.

Maldonado, T. (2002). Técnica y Cultura. El debate alemán entre Bismarck y Weimar. Buenos Aires: Ediciones Infinito.

modernabuenosaires.org

Pevsner, N. (2011). Pioneros del diseño modern: de William Morris a Walter Gropius. Buenos Aires: Ediciones Infinito.

Robertson, P.; Sharples, J. y Nicky Imrie, N. (2014). Mackintosh Architecture: Context, Making and Meaning www.mackintosh-architecture.gla.ac.uk, 2014. (2020). Hermann Muthesius. Architect and writer. Disponible en https://www.mackintosh-architecture. gla.ac.uk/catalogue/name/?nid=MuthHer

Salinas Flores, O. (2001). Historia del Diseño industrial. México: Trillas.

Salinas Flores, O. (2002). Clara Porset, una vida inquieta , una obra sin igual. México: Facultad de Arquitectura de la Universidad Nacional Autónoma de México.

Salinas Flores, O. (2006). Inventando un México moderno. El diseño de Clara Porset. México: Coeditado por Museo Franz Mayer. Difusión Cultural, Centro de Investigación de Diseño Industrial, Universidad Nacional Autónoma de México.

Siebenbrot, M. y Shöbe, L. (2009). Bauhaus 1919-1933. Singapure: Parkstone.

Schönberger, A. et alt. (1990). Raymond Loewy. Pioneer of American Industrial Design. Germany: Prestel.

Stachelhaus, H. (1991). Kasimir Malewich. Un conflicto trágico. Barcelona: Parsifal Ediciones. The Met. (2020). Edward Colonna. Disponible en https://www.metmuseum.org/art/co llection/search/487481.

Torrent, R. y Marín, J. (2005). Historia del diseño industrial. Madrid: Ed. Cátedra.

Whiteway, M. (2001). Christopher Dresser. 1834-1904. Milán: Skira.

Wilhide, E. (2017). Diseño. Toda la historia. Barcelona: Editorial Blume.

Zabalbeascoa, A. y Rodríguez Marcos, J. (1998). Vidas construidas. Biografías de arquitectos. Barcelona: Editorial Gustavo Gili. 
Ynzegna Acha, B. (2017). Hannes Meyer: Proyecto, conceptos y trayectoria. Buenos Aires: Diseño.

Abstract: From the beginning of the history of industrial design -with an emphasis on furniture design- a varied universe of professions, materials, technologies, ideologies and economic interests will delineate an object repertoire, with the consequent establishment of a canon. Its protagonists, from the nineteenth century to the present, formed a network of migratory movements, motivated by their own interests, in some cases, or, in others, as a consequence of the political, social and cultural context. This paper will survey these migrations and study their influence on the training of professionals, the construction of teaching programs, the production of material culture and, ultimately, the expansion of the canon.

Keywords: design - furniture - migration - history - teaching - center - periphery - canon.

Resumo: Desde o início da história do desenho industrial -com ênfase no design de móveis- um universo variado de profissões, materiais, tecnologias, ideologias e interesses econômicos vão delinear um repertório de objetos com o conseqüente estabelecimento de um cânone. Seus protagonistas, desde o século XIX até a atualidade, vão constituir uma rede de movimentos migratórios motivados por interesses próprios, em alguns casos, ou em decorrência do contexto político, social e cultural, em outros. Este artigo faz um tour por essas migrações e estuda sua influência na formação de profissionais, na construção de programas de ensino, na produção da cultura material e na expansão do cânone.

Palavras chave: design - mobiliário - migração - história - ensino - centro - periferia cânone.

[Las traducciones de los abstracts fueron supervisadas por el autor de cada artículo] 